\title{
THE IMPACT OF INTERNET ADDICTION ON UNIVERSITY STUDENTS AND ITS EFFECT ON SUBSEQUENT ACADEMIC SUCCESS: A SURVEY BASED STUDY
}

\author{
Sushma Mishra, Robert Morris University, Mishra@rmu.edu \\ Peter Draus, Robert Morris University, draus@rmu.edu \\ Natalya Goreva, Robert Morris University, goreva@rmu.edu \\ Gregory Leone, Robert Morris University, leone@rmu.edu \\ Donald Caputo, Robert Morris University, caputo@rmu.edu
}

\begin{abstract}
The technological advent of the Internet has invaded every aspect of student life on all college and university campuses throughout the nation and throughout the world. While the use of the Internet in the academic arena has empowered students to sharpen and refine their skills and communication capabilities in their pursuit of successful strategies of success, it has also opened a Pandora's Door of danger and addiction. Simply stated, it is construed as an Internet Addiction (IA) characterized by an excessive use of student time and resources on online activities. This study uses a survey method of capturing data from a wide variety of college students to determine the various guises of Internet addiction, and the potential consequences of unfettered access. We then focus on the potential consequences arising from the various stages of addiction, and culminate in determining the effect, if any, that this recurrent addiction has on the academic success of the individual student, with the GPA (Grade Point Average) as the final measure of success or failure.
\end{abstract}

Keywords: Internet Addiction (IA), Internet Addiction Disorder (IAD), Survey-based Internet Activities, Academic Success, GPA Criteria

\section{INTRODUCTION}

The goal of this research is to examine the degree to which the students are addicted to Internet usage and the impact of Internet addiction (IA) on their academic success. While most young people today are consistently exploring all phases of Internet connections, there is a plethora of debate as to what constitutes leisurely use of the Internet and where the border lies between such use and a non-transient addiction. Therefore, our first goal is to determine a concise measurement for IA that will distinguish levels and usage patterns that will stipulate when one should be considered addicted and when not. As a result, we developed a comprehensive set of questions to measure this degree of IA.

While there are an abundance of studies about IA, most of them stem from a general definition of addiction. We consider it to be a special addiction type and would like to measure its impact on academic success. In most studies that we examined, the authors reported a negative impact of addictions on academic success. Misapplied Internet usage resulting in academic performance decrements in subsequent grade tabulations were forecast and followed in a major study in the early years of student Internet pursuit [13]. Studies also indicated that addictions take copious amounts of time, thus suggesting that subjects are not able to dedicate enough effort to academic studies, personal relationships, or any other significant parts of their lives. In this study, we specifically examine if this is true in the sphere of Internet Addiction. The second goal of the study is to determine how IA impacts academic success. Finally, throughout the study we differentiated between the time spent on the Internet for academic purposes and leisure. For that purpose the results were measured for both academic and non-academic use of the Internet.

Internet Addiction Disorder (IAD) is a serious problem that modern society is facing at an increasing rate since the turn of the century. The term addiction has a long history and is defined as "compulsive, uncontrollable dependence on a substance, habit, or practice to such a degree that cessation causes severe emotional, mental, or physiological reactions" [16]. Internet addiction also conveys the use of the Internet to the extent that it impacts the quality of 


\section{Issues in Information Systems \\ Volume 15, Issue I, pp. 344-352, 2014}

work, study, and social life [9]. However, the definitions vary in research studies and there is no unified understanding of the term or a unified method of screening IAD [6]. It became recognized in psychology as an addiction only in the mid-90s [3].

With the dramatic increase in Internet use at the turn of the century, the number of people addicted to these activities increased from nearly none two decades ago to $61 \%$ of the population in the most recent years [15]. A variety of Internet activities can lead to addiction: online gaming, gambling, social sites, pornographic exploitation, media, etc. Internet addiction can cause both mental issues, such as lack of social engagement and decreased productivity, and physical health issues, such as back/neck muscular problems, Carpal Tunnel Syndrome, and problems with quality of sleep [21]. Some studies even suggest that Internet Addiction can be physically damaging to the brains of adolescents and young adults [25].

The students represent a class of individuals in a dangerous pursuit, that is, a group that is significantly impacted by Internet addiction syndrome [7], and the situation becomes more and more perilous with the development of the social media and the mobile technology that enhances it. In this study we identified how many college students are poised on different stages of Internet addiction and to what degree Internet addiction impacts their academic success.

The research questions that this study posits are:

RQ1: How does the time spent on the Internet impact academic success?

RQ2: How does the time spent on academic sites impact academic success?

RQ3: How does Internet addiction correlate with increased academic success?

The remainder of the paper is organized in the following stages. The next section presents a critical review of the literature in the area of Internet addiction and academic success. Following the review of the literature, a concise methodology section is presented. This section presents the data collection and analysis strategies for this study. The discussion section, presents an analysis of the implications of the findings. Finally, future research directions are presented and relevant conclusions are drawn.

\section{REVIEW OF LITERATURE}

The purpose of this study is to examine the relationship between Internet addiction and academic performance among university students at the graduate and undergraduate level. Because the Internet has become the most widely accepted channel for information exchange and networking, a danger exists that it could lead to pathological usage or Internet addiction [1]. In the rapidly expanding universe of social media, many themes of Internet addiction are played out in the everyday life experience of the typical college student, with the prevailing emphasis on the cause, effects, restraints and consequences of their actions. Due to the recent surge of social media into our lives, the responses in the research area are still in their infancy, and are yet to be completely defined [29]. This research study will attempt to expand and delineate the relevant issues pertaining to student encounters of a new kind, one that merges their lifestyle into a nascent technological breakthrough. Of critical importance is the theory that college students tend to develop a dependence on the Internet that exceeds other segments of society [11]. We will use the approach that we are aware of the problems, have examined the implications on them and want to test their effect on the final academic performance standard.

Marshall McLuhan contended that a medium or technology forces society and the individual to adapt to it, rather than the individual adapting the technology to the current world [14]. Each technological development fundamentally changes the way the world works. Certainly, the development of the Internet and World Wide Web paved the way for the social media explosion in communications and interpersonal behavior [11]. Use of the Internet on college and university campuses parallels the strong advances of the society at large. While the primary focus of 


\section{Issues in Information Systems \\ Volume 15, Issue I, pp. 344-352, 2014}

the Internet was initially faculty research, it has migrated to the student community, reached the stage of overwhelming acceptance, and is now poised to become a psychological addiction [11].

Many prominent research findings have shown that the academic problems caused by Internet addiction include missing classes, being late for classes, increased risk of being placed on academic probation, and a general decline in study habits [21]. Research on age factors [12] found that college students between the ages of 19 to 24 were the most susceptible to addiction. A numbers of investigators have suggested that addiction to the Internet among college students is dramatically comparable to addiction to drugs, alcohol, violence, obesity, lack of sleep, and nutrition deficiencies [21].

Obviously, there is healthy Internet usage, as well as unhealthy usage. But addiction, also known as online addiction or Internet Addiction Disorder (IAD), comes in many guises [29]), all exhibiting serious consequences. For the purposes of this study, however, we will focus on the relationship between Internet addiction and academic performance, tilting toward the abstract effects and consequences from matriculation to earned GPA (Grade Point Average) attenuation [23].

It is important to note clearly that we are not comparing the use of the computer, per se, to academic achievement, but rather the Internet utilization capabilities of the computer to academic achievement. It is also important to note a clear distinction of direction in that we are examining the total use by students of the Internet, and not just a specific component of social media (such as Facebook) when positioning our research process. Previous research studies on the impact of obsessive technology usage on academic achievement are not cleanly correlated with each other. Many studies have produced differing results, perhaps because there is no clear point at which one becomes addicted to the Internet, and how and when that point might be determined. Positive and negative effects of technology on academic achievement certainly have been documented. Lei and Zhao (2005) researched the specifics of access, acknowledging that quantity is not as important as quality when it comes to technology use and student achievement. Specifically, when the quality of technology use, particularly when obsessive, is not closely monitored and ensured, such computer use may do more harm than good to student achievement in academic spheres. A number of researchers have found that there is a strong correlation between Internet use and academic performance [13]. Especially noted, high school students have reported that not being able to control their Internet usage has impacted their academic work negatively. Kolek and Saunders (2008) found no correlation between Facebook usage and GPA in a sample of students from a public Northeast research university. Similarly, an exploratory survey study reported a negative relationship between heavy Internet usage and academic achievement as measured by selfreported GPA and hours spent studying each week [30]. On the contrary, a more recent study by Kirschner and Karpinski (2010) concludes that there is a significant negative relationship between heavy Internet use and academic performance. Facebook users reported lower mean GPA's and spending fewer hours per week studying on average than Facebook non-users. It should be taken into consideration, the authors report, that the fact that the heavy Internet usage is often a part of the normal study routine of many students, which could be an indication for the results of the study. In other words, when concurrent processes are intertwined with each other, the effect may be amplified or attenuated.

\section{METHODOLOGY}

\section{Data Collection}

The survey population consisted of all students at a small private university. 87 students completed the survey, with a slight difference in gender distribution ( $54 \%$ male, $46 \%$ female). Ages ranged from 18 through 55 . As would be expected, the ages skewed younger with $55 \%$ of the sample 21 years old or younger, but there was a significant adult population with $24 \%$ of the sample being older than 25 . The sample had a fairly normal distribution of students across academic standings centered on the junior year (43.7\%). The sample contained almost $156 \%$ 


\section{Issues in Information Systems \\ Volume 15, Issue I, pp. 344-352, 2014}

graduate students and slightly more than $10 \%$ freshman students. Almost $20 \%$ of the sample worked full time, while almost $44 \%$ worked part-time.

\section{Data Analysis}

The Internet addiction measurement instrument was retrieved from the current PsychCentral website [18]. The original survey was modified according to the context of the specific research problem in the study, which was Internet addiction and academic success. For academic success, the GPA of the students was collected. There are 8 demographic questions on the survey relating to age, gender, college level, work status and student Id. The survey instrument used for data collection has 25 items in total. The data was analyzed using SPSS v21. The survey questions were Likert type questions, mostly on a 5 point scale. Since the data was ordinal, Spearman's correlations were used to determine the relationships. The Internet Addiction index was calculated as a mean score of items from the survey. Academic performance was measured on an ordinal scale based on the GPA score of each student. This scale resulted in a more normal distribution of GPA scores. Prior research had produced a wide range of values for questions on "time spent online" with values ranging up to " 24 hours". For this reason, the dependent variable of "amount of time spent online" was gathered using an ordinal scale, which ranged from "less than 2 hours" to a maximum of "over 10 hours". The work Status used an ordinal scale ranging from full time to part time, to not working at all.

\section{FINDINGS}

RQ1: How does the time spent on the Internet impact academic success?

The academic success was measured through the subjects' GPA (Table 1). First, we examined the GPA and found a significant and moderate negative correlation between GPA and the time spent on the Internet (-.233). This means that the more time one spends on the Internet, the lower the GPA. As expected, the higher the students' GPA was, the higher their satisfaction with the amount of work they did. This correlation was also significant and moderate (.378). There is a significant correlation of .230 between the subjects' GPA and the percent of time they thought they should spend on academic pursuits online. In other words, a student with a higher GPA felt that one should spend more time on the Internet for the academic purposes.

We found it interesting that there was almost zero correlation (.064) between the subjects' GPA and their belief that the amount of time spent online improves academic performance. This means that, in real life, students with a higher GPA spend less time online, but this is not reflected in their views. Similar to this, no correlation was found between the subjects' GPA and the amount of time they believed people should spend online. The above-mentioned facts lead us to believe that the choice of how much time to spend online is not made at a conscious level.

RQ2: How does the time spent on the Internet impact academic success?

A moderate significant correlation of .230 was found between the amount of time spent on academic sites and the GPA (Table 1). Interestingly, a negative (-.221) correlation between the students' GPA and the difference between the percentage of time they spend and the percentage of time they think they should spend on academic sites. In rhis context, students who think one should spend more on their online activities on academic sitse, have a higher GPA. 
Table 1. Correlations between GPA and the Internet use values.

\begin{tabular}{|c|c|c|c|c|c|c|c|}
\hline & & GPA & Time spent & Per_acad & Time acad & Improve & Satisfied \\
\hline \multirow{3}{*}{ GPA } & $\begin{array}{l}\text { Correlation } \\
\text { Coefficient }\end{array}$ & 1.000 & $-.233^{*}$ & $.230^{*}$ & .025 & .064 & $.378^{* *}$ \\
\hline & Sig. (2-tailed) & & .030 & .032 & .819 & .553 & .000 \\
\hline & $\mathrm{N}$ & 87 & 87 & 87 & 87 & 87 & 87 \\
\hline \multirow{3}{*}{ Time_spent } & $\begin{array}{l}\text { Correlation } \\
\text { Coefficient }\end{array}$ & $-.233^{*}$ & 1.000 & $-.323^{* *}$ & $.530^{* *}$ & .071 & -.092 \\
\hline & Sig. (2-tailed) & .030 & & .002 & .000 & .514 & .399 \\
\hline & $\mathrm{N}$ & 87 & 87 & 87 & 87 & 87 & 87 \\
\hline \multirow{3}{*}{ Per_acad } & $\begin{array}{l}\text { Correlation } \\
\text { Coefficient }\end{array}$ & $.230^{*}$ & $-.323^{* *}$ & 1.000 & $.571^{* *}$ & $.302^{* *}$ & .055 \\
\hline & Sig. (2-tailed) & .032 & .002 & & .000 & .004 & .610 \\
\hline & $\mathrm{N}$ & 87 & 87 & 87 & 87 & 87 & 87 \\
\hline \multirow{3}{*}{ Time_acad } & $\begin{array}{l}\text { Correlation } \\
\text { Coefficient }\end{array}$ & .025 & $.530^{* *}$ & $.571^{* *}$ & 1.000 & $.269^{*}$ & .006 \\
\hline & Sig. (2-tailed) & .819 & .000 & .000 & & .012 & .956 \\
\hline & $\mathrm{N}$ & 87 & 87 & 87 & 87 & 87 & 87 \\
\hline \multirow{3}{*}{ Improve } & $\begin{array}{l}\text { Correlation } \\
\text { Coefficient }\end{array}$ & .064 & .071 & $.302^{* *}$ & $.269^{*}$ & 1.000 & $.255^{*}$ \\
\hline & Sig. (2-tailed) & .553 & .514 & .004 & .012 & & .017 \\
\hline & $\mathrm{N}$ & 87 & 87 & 87 & 87 & 87 & 87 \\
\hline \multirow{3}{*}{ Satisfied } & $\begin{array}{l}\text { Correlation } \\
\text { Coefficient }\end{array}$ & $.378^{* *}$ & -.092 & .055 & .006 & $.255^{*}$ & 1.000 \\
\hline & Sig. (2-tailed) & .000 & .399 & .610 & .956 & .017 & \\
\hline & $\mathrm{N}$ & 87 & 87 & 87 & 87 & 87 & 87 \\
\hline
\end{tabular}

RQ3: How does Internet addiction correlate with increased academic success?

The results of the analysis are presented in Table 2. A small negative correlation (-.156) was found between Internet addiction and GPA, which is understandable (the higher the degree of addiction, the lower the GPA). There is a moderate negative correlation between the degree of Internet addiction and the subjects' satisfaction with their academic performance and no correlation between Internet addiction and the belief that the amount of time spent on the Internet increases academic performance. The larger correlation with satisfaction supports the idea that IA does not just mediate time, but has some negative connotation for the people involved. That is, there is a higher correlation between a subject's IA score and their feelings of academic satisfaction that exists between IA and their actual GPA. This is an important finding and it supports the way of looking at IA as "addiction", and not specifically and simply the same as time spent online, even though there still exists a correlation between IA and time spent online (.295). 
Table2. Internet addiction and GPA

GPA Per_acad Time_acad Improv Satisfied IA_Ave Time_spen time_diff

GPA

Correlation

Coefficient

Sig. (2-tailed)

.032

Correlation

$.230^{*}$

1.000

$\begin{array}{rr}.819 & .553 \\ 571^{* *} & 302^{* *}\end{array}$

.000

.151

$\mathrm{t}$

Per_acad

Coefficient

Sig. (2-tailed)

.032

$.571^{* *}$

.000

.004

$1.000 \quad .269^{*}$

.610

.335

$.530^{* *} \quad-.211^{*}$

Time_acad

Correlation

.025

Coefficient

Sig. (2-tailed)

.819

.000

.012

.151

$-.233^{*} \quad-.221^{*}$

Correlation

.064

$.302^{* *}$

$.269^{*}$

1.000

$.956 \quad .165$

$.000 \quad .050$

Improve

Coefficient

Sig. (2-tailed)

.553

.004

012

$.255^{*}-.251^{*}$

.071

$-.053$

Satisfied

Correlation

$.378^{* *}$

.055

$.006 \quad .255^{*}$

$.017 \quad .020$

.514

.629

Coefficient

Sig. (2-tailed)

.000

.610

.956

1.000

$-.092$

$-.240^{*}$

IA_Ave

Correlation

$\begin{array}{ll}-.156 & -.105\end{array}$

$.151-.251^{*}$

$343^{* *}$

.001

.399

.025

Coefficient

Sig. (2-tailed)

$.151 \quad .335$

$.165 \quad .020$

.020

.001

1.000

$.295^{* *}$

.189

Time_spent

Correlation

$-.233^{*} \quad-.323^{* *}$

$.530^{* *} \quad .071$

$-.092$

$.295^{* *}$

.006

.082

Coefficient

$\begin{array}{ll} & \text { Sig. (2-tailed) } \\ \text { time_diff } & \text { Correlation } \\ & \text { Coefficient }\end{array}$

$\begin{array}{rr}.030 & .002 \\ -.221^{*} & -.331^{* *}\end{array}$

.000
$-.211^{*}$

.514

.399

.006

1.000

.085

Sig. (2-tailed)

.040

.002

.050

.629

.025

.082

.435

Finally, no significant correlation was found between any of the demographic characteristics of the subjects and their Internet addiction. In other words, Internet usage does not vary between gender, number of years in school, and work status, and remains stable across those metrics. Spearman correlations were employed between the Internet Addiction scale and the demographic variables. Additionally, correlations were employed against the amount of time spent online. The results are summarized in the table below (table 3). There was a moderate correlation between the work status and the Internet addiction scale. The broadness of the work categories limit the usefulness of this result, but may provide direction for future analysis.

Table 3: Summary of Spearman correlation of demographic variables

\begin{tabular}{|l|c|c|c|c|}
\hline & Gender & Age & Academic Year & Work Status \\
\hline $\begin{array}{l}\text { Internet } \\
\text { Addition }\end{array}$ & -.182 & -.198 & -.206 & .327 \\
\hline $\begin{array}{l}\text { Time spent } \\
\text { Online }\end{array}$ & -.183 & .159 & .056 & .089 \\
\hline
\end{tabular}




\section{DISCUSSION AND FUTURE RESEARCH}

The findings of this study emphasize the multidimensional nature of the construct Internet addiction. The general assumption is that more time spent on the Internet means that students are getting addicted to it but our data does not support this relationship. Our data also suggests that the time spent online does not imply academic success. The efforts to limit the time spent on the Internet do not seem particularly valuable in improving the chances of academic success. Most significantly, the results indicate that there is an inverse relationship between the degree of Internet addiction and academic success. The findings are encouraging considering there is little research in this area of Internet addiction and academic impacts. An initial factor analysis of the data suggests three underlying factors leading to Internet addiction. Factor 1concerns the lack of self-control leading to Internet addiction. Factor 2 suggests a temporal dimension. Factor 3 engages the scope of relationships formed online. However interesting it might be, these aspects of Internet addiction are beyond the purview of the current study. Gaining an understanding of the nature of these underlying factors that constitute Internet addiction would be the defining characteristic of a study worth pursuing in the future. Another area of future research could be development of a research model understanding the antecedents of Internet addiction and its impact on academic pursuits.

\section{Contributions and Limitations}

This study contributes in several ways to the research literature of Internet addiction. First, there is little research available which can establish a relationship between academic success and level of Internet addiction in students. This study adds to the body of knowledge by exploring this important relationship. Second, there are little empirical evidences to establish relationship between time spent of the Internet for academic and non-academic reasons and its impact of academic success. Several studies can stem from this work exploring other dimensions of Internet addiction of level of satisfaction in relationships formed online. Third, this research provides an insight into today's undergraduate students and their affinity towards usage of the Internet for academic and non-academic purposes. University administrators can draw lessons from this study reevaluating the strategies necessary to engage students more fully in academic pursuits. Employers can draw lessons from this study in terms of usage of the Internet in the work place and correlated productivity incursions.

There are certain limitations to this study. One important drawback is that we have examined just one community of students in this study. The unique representation of this particular community in this study might not make the results generalizable across other communities. Also, GPA has been considered as the sole indicator of level of academic success for students. These numbers are reported by students and do not represent the actual GPA of the students. Finally, respondents may have misreported behavioral or demographic information, as we used selfreported rather than direct measures of Facebook use and other variables.

\section{CONCLUSIONS}

This study explored the impact of level of Internet addiction and academic success of students in terms of theory cumulative GPA. Three research questions addressing the relationship between these variables were formed. A survey was developed and conducted in several graduate and undergraduate courses at a private university in western Pennsylvania. Results were analyzed using SPSS. Our empirical findings support some of the anecdotal evidences represented by the popular press. Our findings suggest that the student level of Internet addiction is actually inversely related to their academic success. This is an important finding as there is little research in this domain exploring the relationships between academic success and level of Internet addiction. Limitations are listed and contributions are established. This stream of research in Internet addiction reveals a promising and productive avenue for several associated future research opportunities. 


\section{REFERENCES}

1. Akhter, Noreen, Relationship Between Internet Addiction and Academic Performance among University Undergraduates. Academic Journal, Volume 8(19),October, 2013, pp. 1793-1796.

2. Al Hasib, A, (2009). Threats of Online Social Networks. IJCSNS International Journal of Computer Science, Volume 9, No. 11, pp288-93.

3. Beato, J. (July 26, 2010). Internet addiction: What once was parody may soon be diagnosis. Retrieved from http://reason.org/news/show/internet-addiction-diagnosis on Feb. 19, 2014

4. Brauser, Deborah (2013). Internet Addiction May be as Hard to Kick as Drugs. WebMd, February, 2013 Issue.

5. Brenner, V. An Initial report on the online assessment of Internet Addiction: The First 30 Days of Internet Usage. Available: http://www.ccsnet.com/prep/pap/pap8b/638bo12p.txt.

6. Byun, S., Ruffini, C., Mills, J.E., Douglas, A.C, Niang, M., Stepchenkova, S., Lee, S.K., Loutfi, J., Lee, J.K., Atallah, M., and Blanton, M. (2009). Internet Addiction: Metasynthesis of 1996-2006 Quantitative Research. CyberPsychology \& Behavior, XII(2), pp. 203-207

7. Chou, C, Condron, L., and Belland, J. (December 2005). A Review of the Research on Internet Addiction. Educational Psychology Review, XVII(4), pp. 363-388

8. DeAngelis, Tori D., Is Internet Addiction Real? American Psychological Association, April 2000, Volume 3, No. 4.

9. Fitzpatrick JJ. (2008) InternetAaddiction: Recognition and Interventions. Armenian Medical Network. www.health.am/psy/more/internet-addiction-recognition-and-interventions

10. Internet Addiction Among College Students: Ten Startling trends. Accredited Online Colleges, Retrieved 9/18/13. http://www.accreditedcolleges.com/blog/2011/internet-addiction-among-college-students.

11. Kandell, Jonathan J. Internet Addiction on Campus: The Vulnerability of College Students, Cyber Psychology and Behavior, Volume 1, Number 1, 1998.

12. Kim, J.H., (2004). A Study on the Problem and Policy of Youth Internet Addiction. South Korean Fam. Soc. Work 9(2): 21-34

13. Kubey, R.W., Lavin, M. J., \& Barrows, J.R. (2001).Internet Use and Collegiate Academic Performance Decrements: The Early Findings. Journal of Communications. Volume 51, 366-382, 2001.

14. McLuhan, M. (1964). Understanding Media: The Extensions of Man (rev. ed.). New York: McGraw-Hill, 1964.

15. Moisan, A. (2012). STUDY: How Many People Are Addicted to the Internet and Why. In MarketingAllInclusive.com, retrieved from http://www.marketingallinclusive.com/articole/latestnews/study:-how-many-people-are-addicted-to-the-internet-and-why-10610.html on Feb 19, 2014

16. Mosby's Medical Nursing \& Allied Health Dictionary, 5th ed. (1998) St. Louis: Mosby, p. 321.

17. Nauert, R., Internet Addiction on the Decline in College Students. Psychological Central, Retrieved on Nov. 6, 2013, http://psychological.com/news/2011/06/08/internet-addiction-on-the-decline-in-collegestudents.

18. PsychCentral (2014) Retrieved from http://psychcentral.com/quizzes/netaddiction.htm

19. Razieh, Jalalinejad, The Relationship between Internet Addiction and Anxiety in the University Student. Interdisciplinary Journal of Contemporary Research, May, 2012 University of Isfahan, Iran.

20. Rosen, Larry D. The Hidden Dangers of Social Media Use by College Students. Retrieved 10/1/13. http://www.onlinecollegecourses.com/2012/04/03/the-hidden-dangers-of-social-media-use.html.

21. Saisan, J., Smith, M., Robinson, L., and Segal, J. (2013). Internet \& Computer addiction: Signs, Symptoms, and Treatment. Helpguide.org, retrieved from http://www.helpguide.org/mental/internet cybersex addiction.htm on Feb 19, 2014

22. Stein, R. (2009). Does Facebook Lead to Bad Grades? The Washington Post. Retrieved on 2/25/13. 


\section{Issues in Information Systems \\ Volume 15, Issue I, pp. 344-352, 2014}

23. Tanner, Lindsey. \#Goodluckwiththat: Ban and Limits on Student Use of Social Media on the Internet: The Times, Beaver Newspapers, Inc. Pennsylvania, Nation, Section A, Pg. 5, October 29, 2013.

24. Valkenburg, P.M., Social Consequences of the Internet for Adolescents: A Decade of Research. Current Directions in Psychological Research, Vol.8, No. 1.

25. Waugn, R. (Jan. 12, 2012). Internet addiction can cause physical damage to the brain, just like drugs, say researchers. Retrieved on Feb. 20, 2014, from http://www.dailymail.co.uk/sciencetech/article2085369/Internet-addiction-cause-physical-damage-brain-just-like-drugs-say-researchers.html

26. Walton, Alice G., Internet Addiction, the New Medical Health Disorder, Forbes Magazine, Retrieved Nov. 5, 2013, www.forbes.com/sites/walton/2012,10/02/the-new-mental-health-disorder.

27. Wilson, Gary and Robinson, Marnia. Cupid's Poisoned Arrow. Psychology Today blog. Retrieved 10/30/2013. http://psychologytoday.com/blog/cupids-poisoned-arrow/201203/recent-internet-addictionstudies.

28. Young, Kimberly S., Caught in the Net: How to Recognize the Signs of Internet Addiction, $1^{\text {st }}$ Edition, Wiley, 1998.

29. Young, Kimberly B. Who Gets Addicted to the Internet? Counseling Center, Texas State University. Retrieved 9/18/2013. http://counseling.txstate.edu/resources/iteradd.html.

30. Kirschnera, P. and Karpinskib, A.(2010). Facebook ${ }^{\circledR}$ and academic performance, Computers in Human Behavior, Volume 26, Issue 6, November 2010, Pages 1237-1245 